\title{
Environmental and Health Impact of Paint Products
}

\author{
Ruzena Kralikova, Miriam Pinosova, Frantisek Koblasa, \\ Emil Wessely \& Miroslav Rusko
}
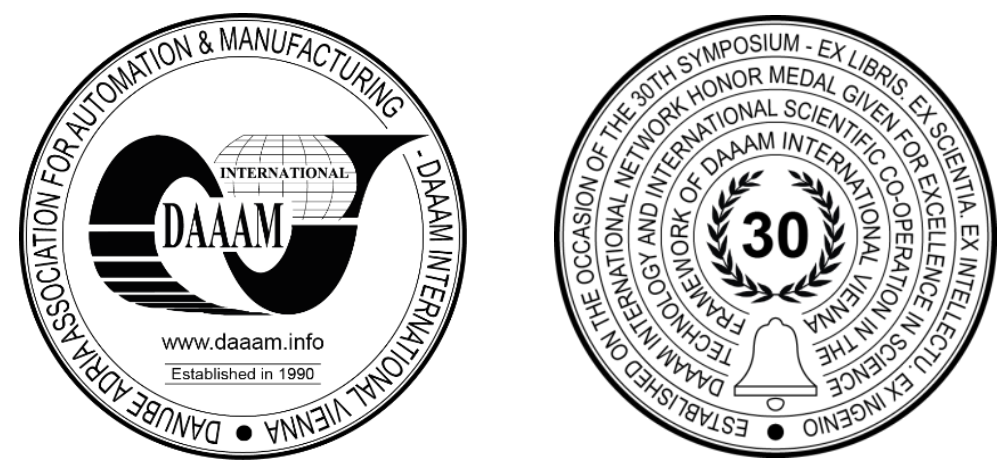

This Publication has to be referred as: Kralikova, R[uzena]; Pinosova, M[iriam]; Koblasa, F[rantisek]; Wessely, E[mil] \& Rusko, M[iroslav] (2020). Environmental and Health Impact of Paint Products, Proceedings of the 31st DAAAM International Symposium, pp.0035-0043, B. Katalinic (Ed.), Published by DAAAM International, ISBN $978-$ 3-902734-29-7, ISSN 1726-9679, Vienna, Austria DOI: $10.2507 / 31$ st.daaam.proceedings.005

\begin{abstract}
The approaches of manufacturing companies to sustainable development are different. However, all business enterprises can contribute to sustainable development and differences can vary depending on the industry, the size of the organization and the management system. Businesses and companies find ways to achieve the goals such as the protection of the environment, social well-being and economic development. Environmental attention in the last decade has seen a shift from production facilities and processes to products with minimal negative impact on the environment and human health. It has been found that interest in voluntary initiatives leads to their spread across a number of companies and in several countries in order to design them in such a way as to achieve optimal efficiency and effectiveness. Voluntary tools such as eco-efficiency, eco-design, product-oriented environmental management systems, sustainable service strategies, product surveillance, supply chain management, eco-innovation, life-cycle costing and environmental labelling are used more frequently. This paper describes voluntary tools that predict the future development and improvement of the eco-labelling schemes for interior and exterior paints and varnishes to minimize their environmental impacts.
\end{abstract}

Keywords: Environment; health; green product; labelling.

\section{Introduction}

This contribution reviews what is known about ecolabelling as an environmental policy tool and as a potential trade barrier. It focuses on well-known Eco labelling programmes that incorporate environmental requirements that need to be addressed if ecolabels are to be designed and applied in ways that support sustainable development. In this review is demonstrated that additional data collection and next research needs to be undertaken if the effects of ecolabelling are to be understood. Many producers demonstrated that pursuing sustainable development strategies makes good business sense and human well being. A company's existence is directly linked to the global environment. In carrying out its activities, a company must maintain respect for environmental principles, and strive towards a society where the global environment is protected. The interconnection of economics with environmental issues is of great significance. 
For the restriction of negative influences aiming at sustainable development of society assurance there are adopted some relevant measures often joined with labelling activities that are having a task to inform, mobilize, regulate an activity to limit or eliminate its influences [11].

The role of business is to contribute to sustainable development. While all business enterprises can make a contribution towards its attainment, there exist some differences by sector and organization size. But all businesses and societies can find approaches that will move towards base goals as environmental protection, social wellbeing and economic development at the same time [18].

Linking environmental issues to economy and finance is an important sphere. Growing load and deterioration of the environment can be interpreted as a result of some external effects interventions. While the positive externalities influence the positive production and utilization functions of other subjects, the negative externalities influence the negative ones. From the analysis of different ways of the environmental protection of the last century end arose that the most effective and the most economic ways of the environmental protection are based on prevention, then a research and a liquidation of causes, which evocate the contamination of the environment [1].

\section{Voluntary methods of the environmental protection}

Environmental attention in the last decade has seen a shift away from production facilities and processes to green products and products with minimal impact on the environment across their life cycle [3]. Was found the interest in voluntary initiatives has resulted in their proliferation across a range of companies and in a variety of countries with the goal to design them to achieve optimum efficiency and effectiveness [13], [15]. Initially, industry viewed voluntary initiatives either as a means of achieving (at best) a flexible, cost-effective and more autonomous alternative to direct regulation, or (at worst) simply a means of avoiding the imposition of binding standards altogether [18].

More often are the voluntary tools as eco-efficiency, eco-design, product-oriented environmental management systems, sustainable service strategies, product stewardship, supply chain management, eco-innovation, costing products over their life-cycle and eco-labelling [10], [14].

\subsection{Ecolabelling definition}

Ecolabelling is a voluntary method of environmental performance certification and labelling that is practised around the world. An "ecolabel" is a label which identifies overall, proven environmental preference of a product or service within a specific product/service category. There are different classifications of labels. In contrast to "green" symbols, or claim statements developed by manufacturers and service providers, the most credible labels are based on life cycle considerations; they are awarded by an impartial third-party in relation to certain products or services that are independently determined to meet transparent environmental leadership criteria [2], [8]. According to the International Standards Organization (ISO) the existing green product certification labels or environmental labels are classified into three typologies whose characteristics are explained below in Table 1 [4].

\begin{tabular}{|c|c|c|}
\hline Type & ISO Number & Description \\
\hline Type I (ecolabel) & ISO 14024 & $\begin{array}{l}\text { - voluntary labels, } \\
\text { - multiple-attribute criteria based, } \\
\text { - third party programme that awards a license or seal or approval, } \\
\text { - authorising the use of environmental labels on products initiating } \\
\text { overall environmental preference of a product within a products } \\
\text { category based on LCA (life cycle assessment), } \\
\text { - needs a third party certification. }\end{array}$ \\
\hline $\begin{array}{l}\text { Type II (self declaration } \\
\text { claims) }\end{array}$ & ISO 14021 & $\begin{array}{l}\text { - voluntary labels, } \\
\text { - verifiable single-attitude environmental claims for issues such as } \\
\text { energy consumption, emissions or recycled content, } \\
\text { - can be first party self-declared manufacturer claims, } \\
\text { - needs only a first party self - certification (issued by producer). }\end{array}$ \\
\hline $\begin{array}{l}\text { Type III (environmental } \\
\text { declaration) }\end{array}$ & ISO 14025 & $\begin{array}{l}\text { - voluntary labels, } \\
\text { - consists in qualified product information based on life cycle } \\
\text { assessment, } \\
\text { - qualified third party determines the environmental parameters, } \\
\text { - then companies gather the required information into the reporting } \\
\text { format and these data is independently verified (e.g. report } \\
\text { cards/information label), } \\
\text { - needs a third party certification. }\end{array}$ \\
\hline
\end{tabular}

Table 1. ISO defined type of environmental labels [12] 
EU Ecolabel Criteria (EC 2010) aims to pull the market by promoting the production and consumption of more sustainable product options. In particular, the Ecolabel is a type-I environmental label (ISO 2018) that can bring added value for companies that invest in eco-innovation and want to communicate the improved environmental performance of their products or services to consumers [17].

Ecolabel identifies products and services that have a reduced environmental and health impact throughout their life cycle [12]. Product policies based on life cycle thinking were therefore developed. However, as no single policy can be capable of addressing all product and sector specific challenges, it was recognised that a combination of pull (voluntary) and push (mandatory) tools is needed (see Fig. 1) [3].

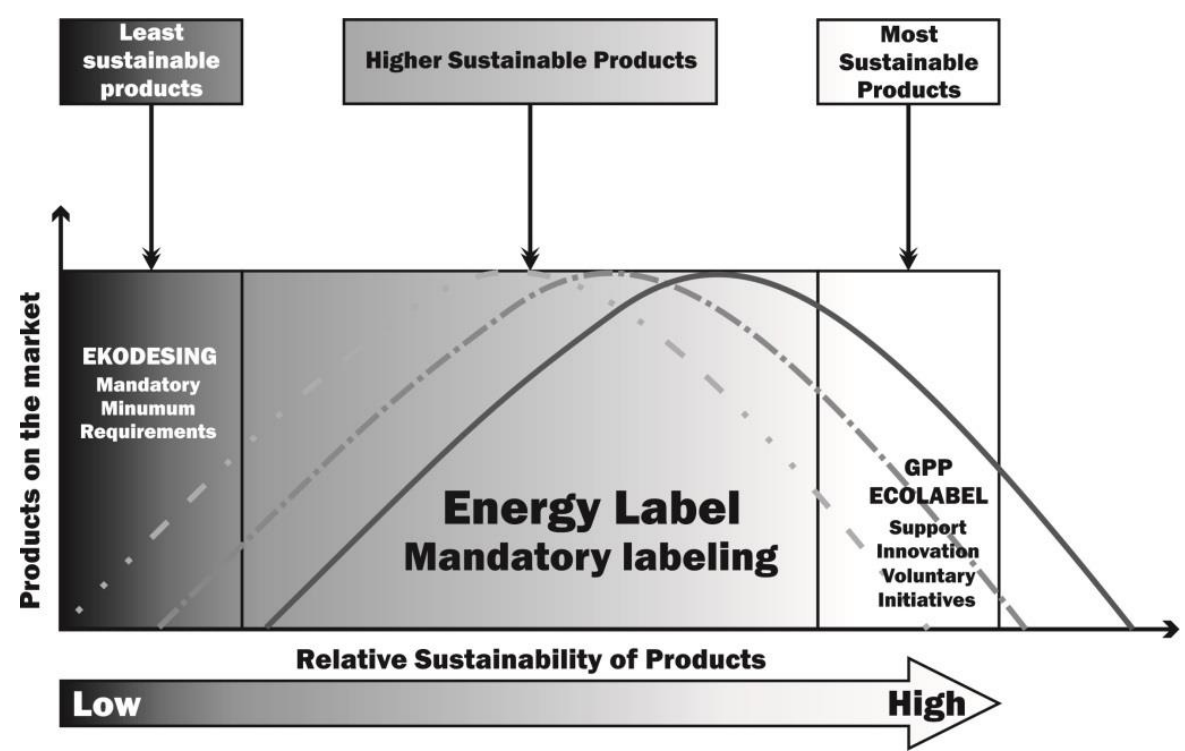

Fig. 1. Environmental Labels Classification (Source: International Standard Organization) [3].

\subsection{Historical development in EU}

Germany was the first country to introduce environmental labelling after 1977. In 1978, the "Blue Angel" was the first European ecolabel to be established. Since then, many international and national labels have followed. In 1989, the Nordic Council of Ministers set up the Nordic Ecolabel and finally in 1992, the EU Ecolabel followed, which combines all European countries in close cooperation with the national label authorities and national label organisations.

The "Blue Angel” and the „Nordic Ecolabel” (the Nordic Swan) as well as the EU Ecolabel are the most wellknown and used Eco Labels in Europe, although there are also other national labels in several countries such as the Austrian Ecolabel, AENOR Medio Ambient from Spain, NF Environment from France, National Programme of Environmental Assessment and Ecolabelling in the Slovak Republic (NPEHOV), Figure 2.
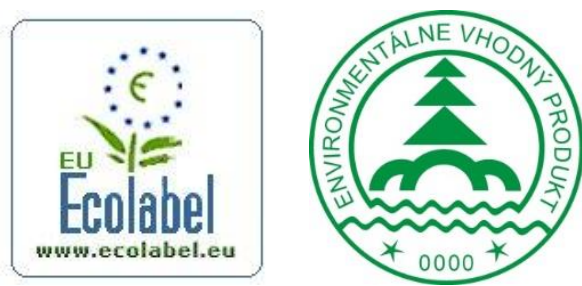

Fig. 2. Mark EU-Ecolabel and Slovak- Ecolabel mark [17].

The popularity of the eco-labels vary in different European and international regions and in different product groups. presents relevant ecolabels that were selected by UNOPS (2009) as reliable for procurement purposes. Also the Global Ecolabelling Network (GEN, 2015) provides an exhaustive list of labels. The overview should give a complete picture of relevant labels in the world market, eco-labels are truly found all over the globe, including in developing countries and countries in transition. The product categories covered by ecolabels include chemicals, textiles, paints, electricity, paper, furniture, building material, cleaning products and services, appliances, hotel accommodation, etc. 


\subsection{Standards contribute to a circular economy}

Through the European and national eco-labelling schemes as EU Ecolabel and Environmentally Friendly Product is more transparent demonstrated that products and services that meet stricter requirements, such as those laid down by generally binding regulations, have a competitive advantage on the market because, through regulation, they are credible for the consumer and are thus a guarantee of environmental quality.

For the entities with environmental thinking, voluntarily joining these schemes, the environmental label represents an important marketing instrument strengthening their positions and recognition in the market. For the consumer with the sense of the environmental and health protection, it is a great help in the correct and responsible selection.

The voluntary environmental protection instruments such as ecolabel, EMAS, Eco design etc. are an integral part of the transition to a circular economy. Voluntary instruments of the environmental policy are of high importance for influencing consumption and production and, at the same time, they can drive the circular economy. In the circular economy, the value of products, materials and resources is kept in the economy for as long as possible, and the generation of waste is reduced quantitatively and improved qualitatively. The Environmental Technology Verification Program has been created too, to enable customers and investors to know the performance and environmental benefits of different technologies. However, the success of all these instruments is based on voluntary commitments, on a voluntary change of production and consumption.

\subsection{Ecological behaviours of customers}

A green product is a sustainable product designed to minimize its environmental impacts during its whole life-cycle and even after it's of no use [7], [9], [12]. Based on the theoretical analysis, research hypotheses were drawn in order to compare the results of a study from surveys oriented to interest of customers for buying environmental suitable products. Several surveys have been carried out to determine the level of consumer awareness of environmental labels in the SR [5], [10], [11]. Respondents answered the question "In which area would you prefer environmentally friendly products?". According to the questionnaire surveys conducted in Slovakia, which dealt with the perception of environmental labelling of products by Slovak consumers suggests that most respondents would prefer environmentally-friendly products in: vehicle, paint and varnish groups, cleaners, batteries and services (Figure 3).

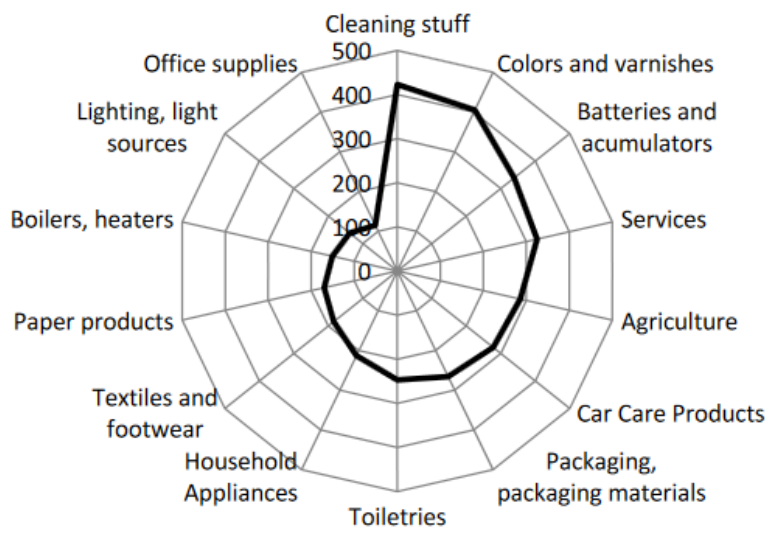

Fig. 3. Preferences of environmentally friendly products according to use field [5]

But from the studies based on questionnaire surveys it has been reported that higher price out weighed ethical considerations in case of purchase of green products [5]. Lack of economic resources of consumers was found to magnify the effect of price and act as a barrier to purchase of green products and low price sensitivity of consumers was found to positively affect green purchase behaviour. The high price sensitivity negatively affected green purchase behaviour of consumers. It is thus clear that high price negatively influences green purchase intention and behaviour. Conversely, others studies revealed that, the consumers 'purchasing decisions are significantly affected by the consideration of the product impacts on the environment, and based on this empirical evidence should be high lighting the significant role of eco-labels in increasing the perceived behavioural control in consumers [10], [11].

\section{Ecolabel of indoor and outdoor paints and varnishes}

The production of more sustainable, 'healthier' paints has been in response both to consumer pressure, and tighter regulations around the VOC content of paints and varnishes. Ecolabelling can help consumers make more informed choices and identify which paint creates are more dangerous to us and our environment. 
The certification mark, based on the paints' compliance with their testing standard, helps determine relative safety, health impact as well as and quality of the paints for users. The status quo of the EU Ecolabel criteria was analysed through a desk research in a first step, making use of the publicly available information of the European Commission and selected publications. The process of the development and review of existing EU Ecolabel criteria catalogues follows the scheme illustrated below. Member States, the European Commission (EC -DG Environment), and Competent Bodies can present suggestions for new introductions or reviews in consultation with the EU Ecolabel Board (EUEB). The EUEB is made up of the Competent Bodies of the Member States, DG Environment and representatives of citizen and consumer organisations [18].

\subsection{European legislative framework for paints}

Under Regulation (EC) No 66/2010, the EU Ecolabel may be awarded to products which have a reduced environmental impact during their entire life cycle [21]. Regulation provides that specific EU Ecolabel criteria are to be established according to product groups. In order to better reflect the state of the art of the market for this product group and take into account the innovation of the last years, it is considered appropriate to modify the scope of the product group and establish a revised set of ecological criteria, addressed separately indoor and outdoor paints. The revised criteria reflect new requirements on hazardous substances are given by Decision 2014/312/EU establishing the ecological criteria for the award of the EU Ecolabel for indoor and outdoor paints and varnishes [20]. This decision replaced Decisions: No 2009/543/EC and No 2009/544/EC. The criteria aim, in particular, at promoting products that have a lower environmental impact along their life cycle, are of high quality, have good performance and long durability, products which contain a limited amount of hazardous substances and a limited amount of volatile organic compounds. In Europe the paint and coatings industry is under strong pressure to reduce VOC emissions and to cope with increasing regulatory and consumer pressure. The European Eco-label helps to foster the use of cutting edge technology and guides consumers to environmentally friendly products, such as premium-quality waterborne paints and varnishes for e.g. low odour, low to near zero VOC and other toxic emissions (see Fig. 4).
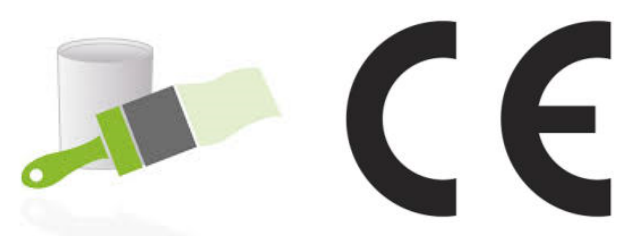

Fig. 4. Eco-label CE (Conformité Européenne) paints and varnishes mark; CE mark [16]

\subsection{The Eco-label criteria for indoor and outdoor paints and varnishes}

The EU Eco-label criteria for indoor and outdoor paints and varnishes reflects the best environmentally friendly products on the market which have high quality and performance standards. The EU Eco-label for indoor and outdoor paints and varnishes "The official European label for Greener Products" guarantees:

- Minimised content of hazardous substances;

- Reduced content of volatile organic compounds (VOCs): x g/l ;

- Good performance for (both) indoor (and) or outdoor use.

Products with improved performance in relation to these aspects should be promoted via the Ecolabel. It is therefore appropriate to establish EU Ecolabel criteria for the product group "paints and varnishes". A transitional period should be allowed for producers whose products have been awarded the EU Ecolabel for indoor and outdoor paints and varnishes on the basis of the criteria set, so that they have sufficient time to adapt their products to comply with the revised criteria and requirements $[19,20]$.

The European Eco-label is an official EU mark for Greener Products. If companies want to show commitment to a better environment are necessary of their products "indoor and outdoor paints and varnishes" to fill criteria and guarantees. Criteria for awarding the EU Ecolabel to paints and varnishes under EU Decision [19], [20], [22]:

1. White pigment and wet scrub resistance.

2. Titanium dioxide.

3. Efficiency in use: Spreading rate (only for white and light coloured paints, including the white base paints used in tinting systems), Resistance to water, Adhesion, Abrasion, Weathering, Water vapour permeability, Liquid water permeability, Fungal resistance, Crack bridging, Alkali resistance, Corrosion resistance.

4. Volatile and Semi-volatile Organic Compounds (VOCs, SVOCs).

5. Restriction of hazardous substances and mixtures: Overall restrictions that apply to hazard classifications and risk phrases, Restrictions that apply to Substances of Very High Concern, Restrictions that apply to specific hazardous substances.

6. Consumer information. 
The product group of "indoor and outdoor paints and varnishes" shall comprise indoor and outdoor decorative paints and varnishes, wood stains and related products intended for use by consumers and professional users falling. We apply paint for decoration, protection, identification and sanitation. The product group of paints and varnishes shall comprise: floor coatings and floor paints; paint products which are tinted by distributors at the request of consumer (nonprofessional) or professional decorators, tinting systems, decorative paints in liquid or paste formulas which may have been pre-conditioned, tinted or prepared by the manufacturer to meet consumer's needs, including wood paints, wood and decking stains, masonry coatings and metal finishes primers and undercoats of such product systems [21].

The product group shall not comprise the following products: anti-fouling coatings, preservation products for wood impregnation, coatings for particular industrial and professional uses, including heavy-duty coatings, powder coatings, UV curable paint systems, paints primarily intended for vehicles, product which primary function is not to form a film over the substrate, e.g. oils and waxes, fillers as defined by EN ISO 4618 and road-marking paints. For the purpose of decision [19], the following definitions are apply:

- Paint means a pigmented coating material, supplied in a liquid paste or powder form, which, when applied to a substrate, forms an opaque film having protective, decorative or specific technical properties and after application dries to a solid, adherent and protective coating.

- Varnish means a clear coating material which, when applied to a substrate forms a solid transparent film having protective, decorative or specific technical properties and after application dries to a solid, adherent and protective coating.

- Decorative paints and varnishes means paints and varnishes that are applied in-situ to buildings, their trim and fittings, for decorative and protective purposes.

- Lasure means coatings producing a transparent or semi-transparent film for decoration and protection of wood against weathering, which enables maintenance to be carried out easily.

- Tinting system means a method for preparing coloured paints by mixing a 'base' with coloured tints.

- Masonry coating means a coating that produce a decorative and protective film for use on concrete, paintable brickwork, blockwork, rendering, calcium silicate board or fibre-reinforced cement.

- Binding primers means coatings designed to stabilise loose substrate particles or impact hydrophobic properties.

- $\quad \boldsymbol{U}$ curable paint system means the hardening of coating materials by exposure to artificial ultra-violet radiation.

- Powder coating means protective or decorative coating formed by the application of a coating powder to a substrate and fusion to give a continuous film,

- In-can preservatives are products used for the preservation of manufactured products during storage by the control of microbial deterioration to ensure their shelf life,

- Dry-film preservatives are products used for the preservation of films or coatings by the control of microbial deterioration or algal growth in order to protect the initial properties of the surface of materials or objects,

- Anti-skinning substances are additives that are added to the coating materials to prevent skinning during production or storage of the coating material.

- Volatile organic compounds (VOC) means any organic compounds having an initial boiling point less than or equal to $250{ }^{\circ} \mathrm{C}$ measured at a standard pressure of $101,3 \mathrm{kPa}$ as defined in Directive 2004/42/EC and which, in a capillary column, are eluting up to and including Tetradecane $\left(\mathrm{C}_{14} \mathrm{H}_{30}\right)$ for non-polar systems or Diethyl adipate $\left(\mathrm{C}_{10} \mathrm{H}_{18} \mathrm{O}_{4}\right)$ for polar systems.

- Semi volatile organic compounds (SVOCs) means any organic compound having a boiling point of greater than $250{ }^{\circ} \mathrm{C}$ and which, in a capillary column are eluting with a retention range between n-Tetradecane $\left(\mathrm{C}_{14} \mathrm{H}_{30}\right)$ and nDocosane $\left(\mathrm{C}_{22} \mathrm{H}_{46}\right)$ for non-polar systems and diethyl adipate $\left(\mathrm{C}_{10} \mathrm{H}_{18} \mathrm{O}_{4}\right)$ and methyl palmitate $\left(\mathrm{C}_{17} \mathrm{H}_{34} \mathrm{O}_{2}\right)$ for polar systems.

- White and light coloured paints are those with a tri-stimulus (Y-value) $>70 \%$

- Gloss paints are those which at an angle of incidence of $60^{\circ}$ show a reflectance of $\geq 60$.

- Mid sheen paints (also referred to as semi-gloss, satin, semi matt) are those which at an angle of incidence of $60^{\circ}$ or at $85^{\circ}$ show a reflectance of $<60$ and $\geq 10$.

- Matt paints are those which at an angle of incidence of $85^{\circ}$ show a reflectance of $<10$.

- Dead matt paints, which at an angle of incidence of $85^{\circ}$ show a reflectance of $<5$.

- Transparent and semi-transparent means a film with a contrast ratio of $<98 \%$ at $120 \mu$ wet film thickness.

- Opaque means a film with a contrast ratio of $>98 \%$ at $120 \mu$ wet film thickness.

\section{The impact of paints and varnishes components to environment and human health}

Paint products as indoor and outdoor paints and varnishes may evaporate hazardous emissions such as volatile organic compounds (VOCs) and formaldehydes. However, paints and varnishes with the ecolabels contain no to low concentrations of hazardous chemical components. Nevertheless, studying the paints packaging revealed that a great amount of paints and varnishes available in the market do contain low concentrations of formaldehyde and VOCs. However, even in low air concentrations, VOCs can cause irritation of the respiratory organs, eye, nose, and throat and lung irritation, headaches, loss of coordination, nausea, damage to liver, kidney, and central nervous system, asthmatic reactions etc. As researched by Mendell, leukaemia, lymphoma and nasal cancer may be relative risks caused by indoor VOCs [6]. 
Most paint is made from three basic ingredients:

- Pigment - provides colour and opacity.

- Binder - acts like a glue in holding the pigment to the surface.

- Solvent - maintains the pigment and binder in liquid form.

The VOC emissions play a crucial role in the photochemical ozone formation of the atmosphere and using paints and organic solvents caused anthropogenic emissions of the VOCs. Acceptable paints, although they contain biocides, include latex, acrylic, and recycled latex paints, assuming they don't contain mercury or lead. Avoid oil- and solventbased paints. The impact of paints and varnishes components to health and environment are assume in the Table 2 .

\begin{tabular}{|c|c|}
\hline Paint components & Characteristic and environmental impact \\
\hline VOCs [23] & $\begin{array}{l}\text { - Most common toxic component of paint is from VOCs. } \\
\text { - Oil-based paints generally contain more VOCs than water-based paints } \\
\text { - Gas off VOCs, depending on the type of paint, they may cause a variety of health } \\
\text { problems like nausea; dizziness; irritation of the eyes and respiratory tract; heart, } \\
\text { lung, or kidney damage; and even cancer. } \\
\text { - When the paint dries, the solvents dissipate into the air: a process called off- } \\
\text { gassing. VOCs continue to give off gas into the air after the paint has dried. } \\
\text { - High impact on health and environment }\end{array}$ \\
\hline Fungicides and biocides [23] & $\begin{array}{l}\text { - All exterior paints have fungicides, and low-biocide paints are not available for } \\
\text { exteriors. Paints also contain toxic fungicides to prevent mildew growth, and } \\
\text { biocides, which are used as preservatives to extend the full shelf life. } \\
\text { - often likely to be hazardous /poisonous heavy metal compounds } \\
\text { - Toxic biocides can be detected in the air five years after paint is applied. Like } \\
\text { VOCs, fungicides and biocides contaminate both indoor and outdoor air. If paint } \\
\text { is not disposed of properly, they can also seep into groundwater. } \\
\text { - High impact on health and environment }\end{array}$ \\
\hline Pigments [23] & $\begin{array}{l}\text { Provides colour and opacity, including both in conventional paints, but also in eco } \\
\text { paints, more pigment, the more protection from UV light. } \\
\text { White pigment (Titanium Dioxide): } \\
\text { - Although titanium oxide is considered inert and safe, its manufacture cannot be } \\
\text { regarded as so benign. } \\
\text { - Titanium Dioxide is made in one of two ways - Sulphate or Chloride processing: } \\
\text { depending on the ore used for extraction, each of which has a significant } \\
\text { environmental impact. } \\
\text { - Best practise is to use paints with as little Titanium Oxide as possible. } \\
\text { - Minimal environmental impacts. } \\
\text { Coloured pigments: } \\
\text { - Some of the toxic chemicals in paints come from the substances used to colour } \\
\text { them. Instead of chemical pigments, look for paints made with all-natural } \\
\text { pigments. } \\
\text { Most contemporary organic pigments are synthesised from coal tar and } \\
\text { petroleum distillates, but plant-based pigments continue to feature amongst 'eco' } \\
\text { paint brands. Synthetic organic pigments are usually quite brilliant and have } \\
\text { good colour strength. } \\
\text { Minimal environmental impacts. }\end{array}$ \\
\hline Silicate mi & $\begin{array}{l}\text { - Generally a very low toxic (limited to user exposure eyes and skin) } \\
\text { - Paint with raw material, transport and energy as being. } \\
\text { - Minimal environmental impacts. }\end{array}$ \\
\hline Solvent [23] & $\begin{array}{l}\text { - Water or organic } \\
\text { - Minimal environmental impacts. }\end{array}$ \\
\hline
\end{tabular}

Table 2. The impact of paint components 
VOCs and Ozone produced as part of human activities is a pollutant and a constituent of smog. Ozone is formed when nitrogen oxides, carbon monoxide and VOCs react in the atmosphere in the presence of sunlight. Although lead has been banned for use in paint for decades, other chemicals commonly found in paint have also been linked with significant health and environmental issues. Most paints and stains contain volatile organic compounds (VOCs) and other chemicals that create toxic fumes that can linger indoors for long periods of time. Some VOCs contribute to ozone depletion while others have known health risks. One of the chemicals linked to illness is propane sulfone, which is widely used in paints and is a powerful known carcinogen. The respiratory system and skin are the most significant routes for poisoning from chemicals in paints and stains. The good news is that low-VOC or noVOC paints and stains are becoming more widely available to the consumer. See our list of products below for some examples. If you must use products containing toxic chemicals, do so only in well-ventilated areas and avoid prolonged exposure. Do not allow children to sleep or play in newly painted rooms until the smell has completely dissipated [6].

\section{Discussion and conclusions}

Indoors air isn't always safe for people if the surface of the furniture, walls and other interior equipment are painted by toxic paints. Toxic interior paints can affect the health of people. Using a paint, finish or lacquer as eco-friendly means that it doesn't contain airborne chemicals or gases that will wreak havoc on health. This study was focused on the paints' properties and the importance of ecolabels for paints and varnishes. The consumer creates their own personal value of product quality which helps during the process of making decisions about buying the product. All external and internal features and characteristics of the product affect the consumer behaviour. Important role in consumer behaviour is safety and environmental labelling and brand. Provides a means of receiving the relevant information for the purpose of mediation of knowledge. Basic right of every consumer's need for information to enable it to protect their own health based on the information obtained from the brands mentioned on the product with which it comes into contact.

Users are today more sensitive to the protection of the environment and would like to buy more environmentally friendly products, provided they are properly certified by an independent organisation. With the Ecolabel mark on the products there are offers of a reliable guide to easily identify the good environmental performers available on the market. Despite the fact that in SR there was no campaign about the ecolabelling programme it is sensible to label the products because it strengthens the feeling of the public about the environmental protection as in some countries. By means of environment-friendly product labelling the customers get guaranteed information about the products respecting the environment. The role of successful implementation of environmental labels is especially the provision and availability of information about the products.

Ecolabelling crosses the real-time boundaries of market entities as regards positive impacts on the environment and the environmental consequences of the pre-production phase, production, use and disposal of waste related to a certain product. It can contribute in a decisive degree to establish the right relationship of the market players with the environment elements, their protection and creation, to increase caution and reduce risks in decision-making processes and prevention of damage and losses in the environment and, eventually, to increase the economic efficiency of activities and their results. Public knowledge of the rationale for granting the ecolabels enables to inform the consumer in a non-violent and relatively fast manner about the positive approach of producers and importers to the solution of environmental problems, as well as about harming effects of various substances and processes on environment and thus to generally increase the level of public knowledge on the problematic issues of environmental protection and benefits of buying and using environment-friendly products. Good communication and effective promotion would increase the knowledge of consumers on the advantages of buying environment-friendly products. This would also have an impact on increasing the sales of products and services bearing the environmental label and thus enhance the current as well as potential producers to further activities.

EU Ecolabel Criteria aims to pull the market by promoting the production and consumption of more sustainable product options. In particular, the Ecolabels a type-I environmental label (ISO 14024) that can bring added value for companies that invest in eco-innovation and want to communicate the improved environmental performance of their products or services to consumers [18]. Product policies based on life cycle thinking were therefore developed. However, as no single policy can be capable of addressing all product and sector specific challenges is necessary a combination of pull (voluntary) and push (mandatory) tools is needed. The problem is that there is not enough data on which to base assessments of the effectiveness of these tools. There are not even exhaustive methodologies for conducting assessments. This problem should to be spreaded to government organisations and intergovernmental bodies and regulatory institutes. In this light, the most significant characteristic of ecolabelling or certification programmes is that they provide proof of compliance. Market actors are also increasingly prepared to prefer companies that provide this proof. The future research would be oriented to investigate the need for a label in the each kind od products individually as well as issues of design relating to the labels from the consumer side. With increasing consumer demand for transparency and the rapid digitalisation of packaging, labelling/eco-labelling is necessary cause product information accuracy is becoming more and more important. Thus, next research could help encourage eco-innovation processes through ecolabelling in order to meet environmental expectations. 


\section{Acknowledgments}

This paper was written in the framework of the project No. KEGA 1/045/2018 „Transfer of the latest findings of research into processing textbook Environmental aspects of design engineering objects -Ecodesign"solved at Technical University of Kosice and partly supported by the Student grant competition of the Technical University of Liberec under the project "Optimization of manufacturing systems, 3D technologies and automation" No. SGS-2019-5011.

\section{References}

[1] Cascio, J., Woodside, G. \& Mitchell, P. (1996). ISO 14000 Guide, The New International Enviromental Standars. McGraw-Hill, New York, pp. 3-217.

[2] Ciecińska, B., Sobotová, L., Gągała, I. (2017). Surface laser treatment as an innovative and ecological technology for adhesive bonding, Proceedings from SGEM Conference. Vol. 17, No.52, pp. 915-922, DOI: 10.5593/sgem2017/52/S20.117.

[3] Cordella, M., Alfieri, F., Sanfelix, J. et al. (2020). Improving material efficiency in the life cycle of products: a review of EU Ecolabel criteria. Int $\mathrm{J}$ Life Cycle Assess 25, 921-935. Available from: https://doi.org/10.1007/s11367-019-01608-8.

[4] Brilhante, O. \& Skinner, J. (2015). Green labels and certification process Available from: https://www.ihs.nl/en/media/2017-11-greenlabels. Accessed on: 2020-08-13.

[5] Kralikova, R.; Rusko, M. \& Wessely, E. (2017). Ekolabeling as Development Facilitator of the Environmentally Oriented Product Policy, Proceedings of the 28th DAAAM International Symposium, pp.0124-0130, B. Katalinic (Ed.), Published by DAAAM International Austria, ISSN 1726-9679.

[6] Mendell, M.J. (2007). Indoor Residential Chemical Emissions as Risk Factors for Respiratory and Allergic Effects in Children: A Review. Indoor Air, No. 4, Vol. 17, 259-277.

[7] Mikulić, I., \& Stefanić, A. (2018). The Adoption of Modern Technology Specific to Industry 4.0 by Human Factor. Annals of DAAAM \& Proceedings, Katalinic (Ed.), Published by DAAAM International Vol. 29, pp. 0941-0946.

[8] Polankova, M., Manlig, F. \& Kralikova, R. (2015). Environmental reporting in the enterprise and related issues. In. MM Science Journal, No. 10, pp. 691-695, DOI : 10.17973/MMSJ.2015_10_201537.

[9] Panainte, M., Caraman, I., Nedeff, V., Inglezakis, V., Lazar, G., \& Barsan, N. (2012). Impact of Green Products on Romanian Consumers, Proceedeings of the 23rd International DAAAM Symposium, 2012, Vol. 23, no. 1, pp. 997-1000, ISSN 2304-1382, ISBN 978-3-901509-91-9.

[10] Rusko, M., Kralikova, R; Mikulova, M., Ilko, J. (2016). Labeling of Products from the Context of Environment, Quality and Safety, In book: DAAAM International Scientific Book. pp.419-434. DOI: 10.2507/daaam.scibook.2016.37

[11] Rusko, M. et al. (2016). The management tools and methods application of the organization to environmental protection, Proceedings of the 27th DAAAM International Symposium, pp.0283-0288, B. Katalinic (Ed.), , ISSN 1726-9679, Vienna, Austria, pp. 0283 -0288, DOI: 10.2507/27th.daaam.proceedings.042.

[12] Rubik, Frieder \& Scheer, Dirk \& Iraldo, Fabio. (2008). Eco-labelling and product development: Potentials and experiences. International Journal of Product Development . Int J Prod Dev. 6. 10.1504/IJPD.2008.020401.

[13] Segerson, K. (2013).Voluntary Approaches to Environmental Protection and Resource Management, Annual Review of Resource Economics, Annual Reviews, vol. 5. no1, pp. 161-180.

[14] Sobotova, L., Badida, M., Dzuro, T. (2019). Analysis of selected technologies of cable recycling, Proceedings from conference ICTEP. pp. 234-239. DOI: 10.1109/ICTEP48662.2019.8968967.

[15] Trif, A., Popan, A. (2019) Study on cutting forces and surface quality in turning C45 steel, Academic Journal of Manufacturing Engineering Volume 17, Issue 4, pp. 182-190, ISSN: 15837904.

[16] The EU Ecolabel for Indoor and outdoor paints and varnishes-The official European label for Greener Products" Available from: http://ec.europa.eu/environment/ecolabel/documents/paints.pdf. "Accessed on: 2019-11- 18.

[17] Knowledge Based Bio-based Products' Pre-Standardization. Green label report (2015). Available from: https: //www.biobasedeconomy.eu/app/uploads/sites/2/2017/03/Green-label-report.pdf. Accessed on: 2019-08-13.

[18] Sustainable development goals (2015). Available from: https://www.iisd.org/business/pdf/business_strategy.pdf. Accessed on: 2020-08-13.

[19] Decision No 2015/886/EU Commission Decision of 8 June 2015 establishing the ecological criteria for the award of the EU Ecolabel for indoor and outdoor paints and varnishes.

[20] Decision No 2014/312/EU: Commission Decision of 28 May 2014 establishing the ecological criteria for the award of the EU Ecolabel for indoor and outdoor paints and varnishes.

[21] Regulation (EC) No. 66/2010 of the EP and of the Council on the EU Ecolabel.

[22] Commission Decision (EU) 2018/666 amending Decision 2014/312/EU as regards the period of validity of the ecological criteria for the award of the EU Ecolabel for indoor and outdoor paints and varnishes.

[23] Icons. Available from: https://www.vectorstock.com/ Accessed on: 2020-08-13. 